\title{
LINGUAGEM E COGNIÇÃO: OS (DES)ENCONTROS ENTRE A LINGÜÍSTICA E AS CIÊNCIAS COGNITIVAS ${ }^{1}$
}

\author{
EDWIGES MARIA MORATO \\ INGEDORE VILLAÇA KOCH \\ (UNICAMP/CNPq)
}

\begin{abstract}
In this article we try to contextualize the relations between Linguistics and Cognitive Sciences from a pragmatic-discursive standpoint. For this purpose, we proceed with a critical study of the streams that, in Linguistics, postulate a close relation between language and cognition, concerning some fundamental notions such as communication, use and context. Finally we list the theoretical bases upon which a conceptual bridge betweeen language and cognition can be established: a relation of mutual constitutiveness, which necessarily passes through the processes of signification and in which discourse intervenes.
\end{abstract}

\section{INTRODUÇÃO}

Este texto procura identificar perspectivas que se abrem quando, em relação ao estudo que caracteriza as Ciências Cognitivas, propõe-se uma empreitada pragmáticodiscursiva para se compreender melhor a natureza do processamento de certos aspectos da cognição humana. Como essa abordagem vem crescendo nos últimos anos na mesma proporção em que deixa seus temas e conceitos básicos imersos na vagueza e em descrições pouco precisas, dedicamos este texto à verificação de fronteiras e umbrais que se projetam na relação da Lingüística com as Ciências Cognitivas.

Sem deixar de levar em conta o debate suscitado tanto pela eventual inserção da Lingüística nas Ciências Cognitivas, quanto pelo tipo de relação que ambas mantêm entre si, consideramos, de antemão, que o estudo das línguas naturais e o funcionamento da linguagem têm nas ciências que investigam a cognição seu lugar garantido. Resta saber se a Lingüística seria uma (das) ciência(s) cognitiva(s) ou se apenas guardaria, de seu posto de observação alocado nas ciências humanas ou sociais, relações com outras disciplinas que também se interessam pelo funcionamento

${ }^{1}$ O presente texto é uma versão resumida de um artigo escrito pelas autoras em 1996. Desde então, muitas questões se tornaram mais claras, outras vêm sendo rediscutidas. Contudo, a julgar pelas atuais reflexões que envolvem linguagem e cognição (e Lingüística e Ciências Cognitivas), o debate continua como a conversação e como a vida. 
cognitivo e suas implicações nos processos lingüísticos, em particular, e na atividade discursiva, em geral.

Se a interdisciplinaridade enfraquece ou não a explicitação do funcionamento da linguagem, se as hipóteses cognitivistas ou interacionistas (ou, ainda, construtivistas) em suas diferentes versões, apontam para determinada ontologia (cognitiva, lingüística, ambas?), se a epistemologia básica deve ou não ter um caráter monolítico são questões que voltam a ter sentido hoje em dia, e com um inusitado caráter de urgência se pensarmos que a complexidade dos fenômenos que são analisados (a memória humana, o processamento sócio-cognitivo da linguagem, as atividades inferenciais, os conteúdos ideológicos e sua manifestação, etc.) resulta totalmente instigante e aponta para o arrazoado de Humboldt (1836/1972) segundo o qual o mundo não é um produto original da linguagem, mas é, ao que parece, de sua responsabilidade. Em outras palavras, na "conquista do cognitivo" (para usar uma expressão de Vergnaud, 1991), parece que não se pode escapar de alguma reflexão (ainda que não explícita) sobre a linguagem e o lingüístico, da mesma maneira que não se deixa de visitar algum modelo matemático ou de se proceder a uma obrigatória "peregrinação" aos verdes campos da Filosofia....

Não é difícil apontar as limitações dos estudos que se pautam pela ótica da exterioridade, seja pela ótica da interioridade. Entretanto, nosso interesse aqui é menos o de apontar os problemas das abordagens fortemente cognitivistas (isto é, inatistas), e mais os das fortemente interacionistas (isto é, desenvolvimentistas) no tratamento de questões que envolvem linguagem, cognição e atividade discursiva. Consideramos que tanto as primeiras quanto as segundas, tomadas apaixonadamente (sob a forma de um anti-biologismo tout court, por exemplo, ou de uma certa negligência em relação às experiências significativas da vida em sociedade, constitutivas do processo de configuração do "real"), acabam exigindo maiores contornos explicativos do que os até hoje fornecidos. Por outro lado, vistas como excludentes entre si, tais abordagens mais parecem mergulhar-nos de vez numa "estagnante aura de mistério" (na expressão de Albano, 1990) do que permitir que exploremos outras vias explicativas para os chamados "mistérios da significação" (Lahud, 1977), nos quais a Lingüística e as Ciências Cognitivas freqüentemente imergem.

As abordagens que vislumbram uma relação do tipo estreito entre linguagem e cognição não oferecem menos problemas que a ótica da exterioridade. Contudo, se nosso interesse for fornecer a elas maiores subsídios teóricos para se firmarem como vias explicativas do fenômeno cognitivo, faz-se necessária uma série de ponderações em torno de suas incompletudes ou vaguezas conceituais e metodológicas. Para tanto, elegemos neste artigo aqueles problemas que nos parecem mais recorrentes ou básicos. Tomemos, assim, as vertentes interacionistas relativas às relações entre linguagem e cognição, que postulam uma inter-relação funcional entre ambas.

Se levarmos em conta as implicações teórico-metodológicas de certos domínios da Lingüística discursivamente imbuídos (como as teorias enunciativas, pragmáticas ou textuais), seremos tentados a procurar estabelecer um quadro relacional do tipo interno (no sentido de constitutivo) entre linguagem e cognição. Para tanto, e levando em conta que essa relação demanda uma articulação necessariamente epistemológica entre 
linguagem e cognição, é preciso também considerar se há uma perspectiva de certo modo compatível com esta Lingüística no interior mesmo das Ciências Cognitivas. Ou criar, a própria Lingüística, um modelo cognitivo pragmático-discursivamente orientado.

A tarefa fundamental de uma perspectiva pragmático-discursiva interessada em processos cognitivos seria apontar uma relação de mútua constitutividade entre linguagem e cognição. Esta relação fundamenta-se em uma tese básica, que qualifica, sob inspiração bakhtiniana (Bakhtin, 1929/1981) e vygotskiana (Vygotsky, 1934/1987), o tipo de mediação entre o lingüístico e o cognitivo: não há possibilidades integrais de pensamento ou conteúdos cognitivos fora da linguagem nem possibilidades integrais de linguagem fora de processos interativos humanos ( $C f$. Morato, 1996). A face empírica de tais postulados encontra-se sobejamente descrita e analisada em inúmeras investigações de patologias cerebrais, em diversos estudos voltados para a aquisição de linguagem pela criança, em modelos ou construtos (cognitivos) de organização da linguagem, ou em trabalhos que tratam do processamento sócio-cognitivo do texto e da construção da textualidade ( $C f$. Koch, 1992, 1995).

Se quisermos verificar o grau de compatibilidade e de distanciamento entre os domínios teóricos lingüísticos mencionados anteriormente, procurando ao mesmo tempo apontar as diferenças que mantêm entre si, bem como as possibilidades de construção de um conjunto de explicações em torno de um mesmo objeto (a saber, a cognição humana), é preciso levar em conta a maneira como abordam temas comuns.

Uma boa estratégia é observar como todas administram certas noções cruciais para o estabelecimento de um quadro relacional do tipo interno entre linguagem e cognição, tais como interação, extralingüístico, contexto, uso. No limite, essas noções dão, por assim dizer, conteúdo e substância às concepções de linguagem e de cognição, e acabam por determinar a qualidade da relação que se estabelece entre ambas. Antes, porém, mencionemos alguns problemas implicados na consideração da linguagem e da cognição como integrantes de mundos não compossíveis.

\section{A RELAÇÃO ENTRE O COGNITIVO E O LINGÜÍSTICO NAS CIÊNCIAS COGNITIVAS}

Há alguns aspectos importantes a considerar quanto a este ponto. O que parece estar em jogo, entre outros interesses, quando as diferentes disciplinas das Ciências Cognitivas lidam com a questão do conhecimento e do sentido, é a separação entre o sentido linguiístico e o não lingüístico, além da oposição entre comunicação e significação.

Uma primeira questão pode ser assim resumida: ou o fenômeno simbólico e/ou cognitivo não tem nada de marcadamente lingüístico (apenas se dá a conhecer pela linguagem) ou, admitindo-se a existência de um mundo simbólico/cognitivo não lingüístico, só podemos concebê-lo à imagem e semelhança do lingüístico. Embora as Ciências Cognitivas optem em geral e deliberadamente pela primeira possibilidade 
(posição que, de resto, não se interessa pelo que há de lingüístico além da forma), algumas vertentes da Lingüística têm oferecido importantes reflexões que a contestam.

É preciso, ainda, considerar que, a despeito da evolução das teorias lingüísticas sobre a questão do sentido (que englobam a apropriação social da linguagem, não opõem comunicação e significação de maneira tautológica, apontam para a dimensão interativa dos processos de significação), a noção ideacional de signo predomina nos estudos que envolvem linguagem e cognição. As teorias intelectivas ou representacionais de linguagem, assim, se reúnem em "busca do cognitivo" seja na mente das pessoas, seja nas formas sociais de condutas humanas, com o objetivo de descrever o processamento do discurso ou a maneira pela qual são fixadas as representações e processos de significação qualificados de uma forma algo geral como fenômenos "extralingüísticos".

O problema do "extralingüístico" nos leva em direção à existência de um social, um contexto, um uso, uma cognição à margem da linguagem. Se a linguagem é apenas uma das formas possíveis de significação, como conciliar essa idéia com o fato de que é linguagem também o que contribui para a construção de significações extralingüísticas, propriedades tanto do sistema lingüístico quanto de outros sistemas de signos e operações simbólicas? Como reagir ao fato de que mesmo um (meta)discurso sobre a significação não lingüística (como o das Ciências Cognitivas) depende inteiramente da linguagem e dos efeitos de sentido que provoca? Em suma, o que é a significação, se a linguagem existe e o faz apenas mediante as experiências significativas de vida em sociedade? Se cognição é uma forma de (ser) conhecimento, dependente dos processos de significação, linguagem é, por suas propriedades formais e discursivas, não apenas uma outra forma, mas a própria possibilidade de conhecimento, a "atividade significante e reflexiva por excelência", segundo um postulado típico das correntes enunciativas, que dá forma ao processo de apreensão do real, constituindo-o e sendo constituída por ele.

\section{Uma outra questão a ser pensada diz respeito à noção de contexto.}

Em geral, o contexto tem uma natureza psicopragmática e ocupa uma função restritora ou seletiva na análise de processos lingüístico-cognitivos, fundamental para as atividades de comunicação e de compreensão dos sujeitos ( $C f$. Parret, 1988; Dascal, 1983; Françozo, 1987; Kintsch, 1988; Van Dijk, 1988; Koch, 1992, 1995, entre outros).

Embora no campo da Lingüística a noção de contexto tenha sido negligenciada por muito tempo, nas últimas décadas ela vem ganhando importância sobretudo sob a forma de uma distinção capital para os estudos sobre a produção e interpretação de enunciados, bem como para a identificação de referentes e de processos de implicitação: trata-se da diferenciação do cotexto (lingüístico) em relação ao contexto (situação extralingüística). Ambos, cada um à sua maneira, e ainda que apresentem um estatuto pouco claro, têm papel importante na construção da (inter)textualidade e no reconhecimento de processos pragmáticos e discursivos em jogo nas práticas lingüísticas cotidianas. Isso torna a idéia de contexto integrada às atividades discursivas, e não alheia ou meramente subsidiária em relação a elas. 
O que nos parece complicado na remissão ao "contexto" enquanto categoria explicativa de fatos lingüístico-cognitivos, à semelhança do que ocorre com a noção de interação, é sua vagueza (ou amplidão) conceitual. Ou seja, não raras vezes, o contexto parece operar lá onde a linguagem não está presente, lá onde o social está mitigado em meio à tipologia de contextos, lá onde a representação (mental) não é evidente.

Entendemos que a escolha do contexto como parte da explicação para a questão do sentido ("o que isso - uma palavra, uma ação, um discurso, um signo verbal ou não verbal - quer dizer?") se dá por necessidade, não por razões meramente extralingüísticas ou cognitivas. Se o contexto parece estar sempre coadjuvando ou construindo o sentido, ou atuando em conjunto com processos de significação, apontado sua direção e dando-lhes sustentação, seria ele um domínio interpretativo indispensável à cognição (e ao seu estudo)? Caso a resposta seja afirmativa, é interessante observar que nem sempre um conjunto de contextos é capaz de dar conta do fluxo de sistematicidades e indeterminações que rege os processos de significação.

Ainda que concordemos com Parret quando ele afirma que o contextualismo é uma arma contra a ameaça do psicologismo (1988:209), a interpretação de contextos, prévia a qualquer processo de significação em jogo, parece ter mais a ver com circunstâncias de uso de objetos lingüísticos ou cognitivos do que com sua constituição. Em outras palavras, o que se critica aqui é o recurso ao contexto visto como habilidade (extrínseca) dos sujeitos, e não uma construção (discursiva) dos processos de significação. Para Koch (1995), por outro lado, a inserção do contexto como problemática lingüístico-cognitiva deve passar pelo viés de uma concepção dinâmica do processamento de diferentes contextos, integrados de maneira heurística e seletiva aos processos de significação. O contexto é, pois, esse lugar onde se constroem e se reconstroem indefinidamente as significações, o árbitro das tensões entre as sistematicidades e as indeterminações do dizer e do mostrar, do dito e do implicado. Por um lado, ele apresenta-se como sendo parcialmente estruturado por contingências próprias de um lugar, de uma situação interlocutiva, de um universo interpretativo, de uma ação simbólica humana. Tendo ao mesmo tempo um papel estruturante, o contexto, por outro lado, cria e enforma os processos de significação, dando-lhes "representabilidade".

Finalmente, cabe-nos mencionar a noção de uso, talvez a mais complicada entre as evocadas aqui. Alguns estudos psicolingüísticos ou pragmáticos referem-se tanto ao uso da linguagem para fins comunicativos quanto ao uso cognitivo da linguagem. Françozo resume bem a natureza desses dois tipos de uso, seguindo Dascal: "a distinção entre a sócio-pragmática e a psico-pragmática é a distinção entre os fatores pragmáticos 'externos' que têm a ver com a percepção do 'input' lingüístico e sua interpretação em uma dada situação, e os fatores pragmáticos 'internos' que influenciam o desenvolvimento das operações cognitivas, e que de alguma forma envolvem a linguagem" (1987:228). Se os fatores externos apóiam-se na linguagem e nas informações contextuais para produzir uma representação não lingüística (ou o inverso, produzem 'output' a partir de uma situação não verbal), os fatores internos responsabilizam-se basicamente pelo inverso: a linguagem seria uma espécie de produto das operações mentais. Assim, se Sociopragmática é uma teoria acerca da 
determinação contextual (não lingüística) da linguagem, Psicopragmática é uma teoria acerca da determinação do 'ambiente lingüístico' do pensamento. Nas palavras de Françozo: "abordar a linguagem a partir de uma perspectiva psico-pragmática é abordá-la não como determinada pelo contexto, mas sendo, ela própria, parte do contexto" (op.cit.).

Embora esse construto teórico seja sem dúvida interessante, em parte porque leva em conta, explicitamente, os usuários da linguagem (e da cognição, podemos dizer) e a situação discursiva em que estão inscritos, resta ainda um número considerável de questões a exigir maiores contornos explicativos. Em geral (isto é, não apenas nas vertentes mencionadas acima), a idéia de conhecimento prevê uma acessibilidade entre objetos lingüísticos e cognitivos que só ganha sentido mediante a noção de uso. $\mathrm{Na}$ concepção cognitivista, o uso refere-se, vale lembrar, a capacidades inatas (que são fixadas pelas experiências) responsáveis pela categorização (representação mental) do real. A descrição da categorização, por sua vez, tem um papel fundamental na explicação das estruturas de modelos lingüísticos e cognitivos.

Ora, poderíamos perguntar, se a existência do uso é prévia às experiências significativas do sujeito, não estaríamos diante de uma noção anti-interacionista, subordinada a um misterioso conhecimento apriorístico; não estaríamos às voltas, nesse caso, com o velho mito da telepatia, que às vezes ainda parece encantar cientistas modernos?

Desde que o conhecimento não ocorre no vácuo, ou seja, não se dá fora das experiências significativas do sujeito com as referências do mundo ou das ações simbólicas humanas, a noção de atividade, na acepção depreendida dos postulados de Vygotsky (1934/1987) sobre a o funcionamento sígnico-cultural da vida mental, poderia ser uma alternativa interessante às aporias cognitivistas relacionadas à explicação do acesso categorial (representação mental) da linguagem ao real. A própria idéia de acesso, nesse caso, daria lugar à reversibilidade ou à ação recíproca entre linguagem e cognição, possível por uma "mediação" necessariamente simbólica entre ambas e as referências do mundo sócio-cultural. Com isso, estaríamos assumindo o paradoxo da interdisciplinaridade no tratamento de fenômenos cognitivos. Tal paradoxo, é bom lembrar, advém da impossibilidade de se relacionar diretamente dois objetos - linguagem e cognição - cujas problemáticas semiológicas particulares são distintas, ainda que um não exista de uma maneira mais ou menos completa sem o outro.

Como vemos, todas essas noções não são reguladoras nas vertentes de cunho sócio-pragmático (vamos chamá-las assim...) ligadas ou interessadas nas Ciências Cognitivas, embora tracem uma linha divisória entre as abordagens externas e as internas, referentes às relações entre linguagem e cognição. O que ainda parece faltar à necessária coerência epistemológica da postulação de uma relação interna entre linguagem e cognição é uma discussão teórico-metodológica profunda sobre a concepção de linguagem e de cognição em jogo. 


\section{COMENTÁRIOS FINAIS}

Se entendermos a questão cognitiva como uma problemática pragmáticodiscursiva, seremos obrigados a convocar uma teoria do modo funcionamento da atividade mental compatível com o modo de funcionamento da linguagem. Isso porque, a despeito da "inflação panlingüística" apontada por Granger (1971) em tempos idos, a Lingüística, sozinha, não dá conta de fenômenos que, por sua complexidade, exigem arbitragens interdisciplinares.

Entendendo que essa tarefa ainda está por ser realizada, identificamos o problema conceitual como o mais premente em relação aos empreendimentos realizados pelas abordagens genericamente chamadas "interacionistas", nas quais certamente nos incluímos, malgré tout.

Em suma, se podemos identificar uma espécie de fracasso nas tentativas de se incluir o "social" nas teorias interacionistas, é porque elas, na maioria, limitam-se à concepção de linguagem como comunicação (e de interação como processamento dessa comunicação). Um bom ponto de partida para deixarmos de usar a palavra interacionismo como um termo "guarda-chuva" seria qualificar o conceito de interação, que se torna coisa bem diferente se for considerada um lugar de análise ou se for elevada à condição de princípio explicativo das ações simbólicas humanas. O papel atribuído à linguagem em um caso e em outro é capital para essa diferenciação.

\section{REFERÊNCIAS BIBLIOGRÁFICAS}

ALBANO, E. (1990). Da fala à linguagem: tocando de ouvido. São Paulo: Martins Fontes.

BAKHTIN, M. (1981). Marxismo e Filosofia da linguagem. São Paulo: Hucitec.

DASCAL, M. (1983). Pragmatics and the Philosophy of Mind. Amsterdam: John Benjamins.

FRANÇOZO, E. (1987). Linguagem interna e Afasia. Tese de doutoramento. Inédita. (IEL/UNICAMP).

GRANGER, G.G. (1971). Langue et systèmes formels. Langages 21:71-87.

HUMBOLDT, W. (1972). Linguistic variability \& Intellectual Development. Philadelphia: University of Pennsylvania Press.

KINTSCH, W. (1988). The use of knowledge in discourse processing: A construction- integration model. Psychological Review 95:163-182.

KOCH, I. G.V. (1992). A inter-ação pela linguagem. São Paulo: Contexto. (1995). Estratégias pragmáticas de processamento textual. Cadernos de Estudos Lingüísticos 30.

LAHUD, M. (1977). Alguns mistérios da Linguística. Almanaque 5:105-131.

MORATO, E. M. (1995). Significação e Neurolinguística. Temas de Neuropsicologia e Neurolinguística (Damasceno, B.P. \& Coudry, M.I.H. orgs.). São Paulo: SBNp.

PARRET, H. (1988). Enunciação e Pragmática. Campinas: Editora da UNICAMP. 
VAN DIJK, T. A. \& K., W. (1983). Strategies of discourse comprehension. New York: Academic Press. (1988). Cognição, discurso e interação (Koch, I.G., org.,1992). São Paulo: Contexto.

VERGNAUD, G. (1991). Les Sciences Cognitives en Débat. Paris: CNRS.

VYGOTSKY, L. S. (1987). Thinking and Speech - The collected works of L.S. Vygotsky (vol I: Problems of General Psychology), in Rieber, R. \& Carton, A. (eds.). New York: Plenun Press. 